\title{
THEORY AND EXPERIMENT IN PARAMETRIC MINIMALISM: THE CASE OF ROMANCE NEGATION ${ }^{1}$
}

\author{
Giuseppe Longobardi ${ }^{2}$
}

\section{INTRODUCTION AND SUMMARY}

This paper has a double goal: first, it lays down and refines the basic hypotheses on the parametric structure of Romance negative systems that were originally introduced in my presentation at the Venice GLOW Workshop on Dialect Variation in 1987 (especially sections 3-9 and 11-13); then it further elaborates on them (sections 10 and 14-15), and revisits the conclusions (sections 16-22) in light of a more recent minimalist approach to the possible formats of parametric variation (the Principles \& Schemata model, sketched in Longobardi 2005a). More generally, the theoretical focus of the article is on exploring how minimalist research on syntactic diversity could be conducted.

In the spirit of Borer (1984), the parameters of negation can be argued to be essentially encoded in the lexical entries of the sentential negation morpheme and of the negative determiners of each language. No space is left in this framework for such generic notions as (strict or non-strict) 'negative concord' vs. 'double negation' languages. In fact, these notions looked at best epiphenomenal and obsolete already in 1987: in spite of their continued use even in recent literature, they turn out to be both insufficient and unnecessary, and are potentially misleading.

Now, a good deal of the negation parametrisation can be shown to have to do with the feature composition of lexical entries and to be actually nearly 'perfect', in three minimalist senses: first, given Boolean conditions on feature association, the parametric choices exhaust the set of logical

\footnotetext{
1 This is a second version of the article first published in: Language Description Informed by Theory. Edited by Rob Pensalfini, Myfany Turpin and Diana Guillemin. John Benjamins Publishing Company: Amsterdam, The Netherlands. (Studies in Language Companion Series 147) 2014, pp. 217-262. This version was revised by the author and is being republished by LinguíStica under the explicit authorization of the original editor. 2 University of York/Università di Trieste. E-mail: giuseppe.longobardi@york.ac.uk

3 I am indebted to M. Manuela Ambar for first encouraging me to put the content of that presentation in a written form, and to Claudio Bracco for the original inspiring discussion of Piedmontese data. A slightly expanded version of my 1987 hand out was later circulated, and finally published as Longobardi (2003a). More than anyone, I must thank Diana Guillemin for her patient and detailed comments on that version and on a previous draft of this paper, and Manuel Español and Theresa Biberauer for very helpful discussions. I am also grateful to the Cambridge Linguistic Society for enabling me to present some of these ideas to a stimulating audience.
} 
possibilities, determining whether the values of such features may, must, or may not co-occur on one and the same (class of) item(s); second, all the parameters needed for crosslinguistic descriptive adequacy fit into independently attested and restrictive schemata; third, they are shaped by, or interact with, natural third-factor conditions (Chomsky 2005); finally the parametrisation hypothesised is 'complete' in the technical sense that all the typologically possible combinations of values turn out to be attested.

With respect to UG principles, I show how objections against the possible universality of conditions on covert long-distance dependencies, as established by Italian negative operators (Rizzi 1982, Longobardi 1991), can be successfully addressed and eventually dismissed. Furthermore, such conditions are argued to be fully structural principles rather than functional preferences.

\section{A PRINCIPLES\&SCHEMATA MODEL}

The development of parametric typology to account for language and dialect variation has raised a lot of excitement, but also of debate, for the past thirty years now. Some weaknesses of the approach are empirical and methodological: as remarked elsewhere (Longobardi 2003b), much work about parameters has focused on single parameters in pairs of contrasting languages, with little attempt to consider the complex interactions of neighbouring parameters within a submodule, which are able to generate, but also to exclude, exponentially increasing numbers of languages ${ }^{4}$. Other weaknesses are theoretical: parameters, though robustly supported by descriptive work of the past decades, have come to be viewed as not immediately compatible with the spirit of minimalist syntax: they would introduce too much disparate, unconstrained, and evolutionarily unjustified variability into the class of human grammars (especially cf. Berwick and Chomsky 2011, Boeckx 2011), thus ultimately into the innate state of the mind. In particular, a classical Principles \& Parameters approach seems to imply that hosts of unset/unsettable parameters must be attributed to the minds of speakers of particular languages in which they are irrelevant owing to implications from other parameters or variable properties (Baker 2001, Longobardi and Guardiano 2009).

In response to the latter concerns, Longobardi (2005a) put forth the conjecture that parameters should not be attributed to the initial state of the mind $\mathrm{S}_{0}$, but only to the mature state of each speaker's mind (somewhat improperly called 'steady', $\mathrm{S}_{\mathrm{S}}$ ). Only relevant parameters with their settings would belong to this state, while $\mathrm{S}_{0}$ would only be characterised, along with some invariable principles, by few parameter schemata of an equally general and restricted form (Principles \& Schemata model). For example, already almost two thirds of the 63 very tentative DP parameters investigated in 28 languages in Longobardi and Guardiano (2009) may be reduced to only the first 4 of the following abstract parameter schemata, which are variables over classes of features and categories (the latter ideally being sets of cooccurring features) provided by UG:

a. Is F, F a feature, grammaticalised ${ }^{5}$ ?

Cf. Bortolussi et al. (2011) for a method of estimating the orders of magnitude in so conceived parametric booming.

As an approximation, I take'grammaticalized' as obligatorily present (or valued) in a grammatically (generally) rather than lexically (idiosyncratically) definable context. 
b. Does F, F a grammaticalised feature, Agree with X, X a category (i.e. probes $\mathrm{X})^{6}$ ?

c. Is F, F a grammaticalised feature, spread on $\mathrm{X}, \mathrm{X}$ a category?

d. Is F, F a grammaticalised feature, 'strong' (i.e. overtly attracts $\mathrm{X}$, probes $\mathrm{X}$ with an EPP feature)?

e. Does a functional category (a set of lexically cooccurring grammaticalised features) $\mathrm{X}$ have a phonological matrix $\Phi$ ?

f. $\quad$ Is F, F a grammaticalised feature, checked by the minimal accessible category of type $\mathrm{X}$ (or is pied-piping possible)?

Some reasons may suggest the possible inclusion of the other two schemata (1)e. and f. above (inspired by Kayne's 2010 work and by Biberauer and Richards 2007, respectively) ${ }^{7}$.

Later, Gianollo, Guardiano and Longobardi (2008: 120) suggested that a further "potential candidate for schema status is represented by lexical-syntactic parametrization regarding the encoding of some universally definable features - say, $[ \pm$ pronominal $],[ \pm$ anaphoric $],[ \pm$ variable $],[ \pm$ definite $],[ \pm$ deictic $]$ and so on - in different categories, .... for example ... lexical items. This latter schema was most insightfully, to our knowledge, used by Sportiche (1986), to account for the peculiarities of Japanese zibun and kare as opposed to English anaphors and pronouns." Sportiche (1986) suggested that different languages may distribute certain valued features on different bundles of other valued features (basically, the feature +Bound Variable seems associated also with -Anaphoric, +Pronominal in English, but only with +Anaphoric, -Pronominal in Japanese). Therefore, we may naturally envisage at least two more parameter schemata, essentially exhausting the Boolean conditions on the notion of feature assignment to a category:

(1) a. Are $f_{1}$ and $f_{2}$, two grammaticalized feature values, associated on $X, X$ a category?

b. $\quad$ Are $\mathrm{f}_{1}$ and $\mathrm{f}_{2}$, two feature values associated on $\mathrm{X}$, disjunctively (i.e. optionally) or conjunctively (i.e.

obligatorily) associated?

\footnotetext{
6 Optimally, the domain of probing (i.e. the scope of application of Agree) should be determined by universal properties of grammaticalized features and categories, and from variation affecting the latter (e.g. cf. section 17 below); hence (1)b. could perhaps be eventually eliminated from parameter schemata and the relative labour divided between (1)a. and (1)d. However, some dimension of variation in that spirit has probably to be maintained at the level of externalisation properties, e.g. ruling whether head movement takes place in a language to form, say, $\mathrm{N}+$ enclitic definiteness or V+T clusters. Further questions arise with respect to clitics in general (Roberts and Roussou 2003, Roberts 2010).

7 (1)e is taken to define whether some bundle of universal meaning features is always null in the lexicon of a certain language. It should not be confused with classical conditions on whether an X drops its phonological matrix $\Phi$ in a subset of environments (e.g. null arguments, V-projection deletion etc. among very many examples: cf. Rizzi 1986, Lightfoot 2006). Such phenomena, e.g. null arguments, are obviously parametrised: it remains to be seen if the variation of these environmental conditions is a further primitive schema, or is always predictable from two other possible sources: first of all, schema (1)a. (i.e. non-grammaticalization of certain features, as is plausible for several properties of East-Asian languages, in the spirit of Kuroda 1988); second, independent (e.g. morpho-phonological) properties, as hinted at, e.g., in Longobardi (1996) for null pronominal genitives of construct-state constructions.
} 
Obviously, one would like to reduce even (2)b to a Yes/No question format, like the other schemata: after all, there are only two possibilities here, in a Boolean system, thus one excludes the other. I will return to the issue of the formulation later and will make crucial use of this suggestion (section 19).

So restrictive a theory of schemata would imply, among other things, that most other conceivable variations are disallowed: e.g. if grammaticalized at all, a feature is first-merged into a universally defined position and moved, if necessary, under universal conditions on checking (i.e. on Agree). Also, Gianollo, Guardiano and Longobardi $(2008,120)$ note that under the schemata above even the locus of interpretation of each grammatical feature must be universal, not parametrised, a welcome conclusion called the Topological Mapping Theorem. In other words, such a Principles \& Schemata model may easily incorporate/derive a theory of the universality of D-structure and Logical Form, in more traditional terms, or of well corroborated cartographies of functional heads.

In addition to its restrictiveness and to downsizing the explicanda for an evolutionary theory of UGallowed variation, a Principles \& Schemata model has the advantage of factoring out a good deal of the pervasive implicational structure of parameter systems. Thus, at least some of the cross-parametric implications whose existence was pointed out in Baker (2001) and especially in Longobardi and Guardiano (2009), Longobardi (2012) will not have to be stipulated individually, now, but can just follow from general logical implications among schemata themselves. For example, all parameters of schemata (1)b. and (1)c. will be implied by those of schema (1)a. (unless F of (1)b. or (1)c. is universally grammaticalized); in turn, all parameters of schema (1)d. will be implied by those of schema (1)b. (unless, again, the Agree in question is universal).

Moreover, subset relations among the ranges of Xs or of Fs in the schemata above may automatically provide for another amount of the crossparametric implicational structure: eventually some of the instances of Roberts' (2011) prolific notion of 'hierarchies' could derive from the formulation of schemata.

An interesting research strategy (called 'parametric minimalism' in the references above) now consists precisely in trying to determine if all or most known parameters, e.g. in further domains of grammar, may fall into such schemata, and in proposing few others only if absolutely necessary to accommodate new cases of parametrisation. This strategy would represent a move from descriptive and explanatory adequacy toward a level of evolutionary adequacy (Longobardi 2003b). Newly proposed parameters should accordingly be shown not only to be settable from primary evidence but also to conform to general expectations on their form.

On these grounds, let us turn to Romance negation.

\section{BACKGROUND}

The theory of negation, thanks to the work of many colleagues, has made much progress since Longobardi $(1987)^{8}$. These important contributions will not be discussed in any detail here, though,

\footnotetext{
8 Cf. Laka (1990), Haegeman and Zanuttini (1991, 1996), Vallduví (1994), Quer (1993), Ladusaw (1993), Español-Echevarría (1994), Progo-
} 
for a number of reasons, in addition to obvious limitations of time and space.

First of all, for philological correctness, since one of the aims of this article is to faithfully recapitulate the generalisations arrived at in my 1987 presentation $^{9}$, without appropriating others scholars' later insights and merits.

Second, because I believe that (modulo the very relevant discoveries of Español-Echevarría 1994) the relevance of the macroscopic questions formulated in 1987 has not been substantially outdated by the many new contributions, in spite of their greatly magnifying the resolution of the picture.

Third, because I aim to explore the methodological claim made in Longobardi (2003b), namely that flashes of insight on the form and clustering structure of parametric variation can be gained even in relative abstraction from the growing understanding of the single phenomena involved: to do so, it is useful to analyse together a number of 'contiguous' parameters interacting within the same compact module of grammar (the Modularised Global Parametrisation strategy), the negation system offering one such promising testing ground.

The final reason is that the focus here is not on axiomatizing the theory of negation itself, but rather on reconciling its parametric generalisations with a principled model of variation.

The guiding questions of Longobardi (1987, 2003a), which have remained otherwise largely unresolved to date, were ${ }^{10}$ :

how many primitive differences, within the Romance (vastly inter-comprehensible) diasystem, produce the observed variety in cooccurrence of negative phrases with the sentential negation?

Why is it the case that the generalisations on long-distance dependencies affecting negative phrases, in parallel to wh-phrases, in French and Italian (Kayne 1981, Rizzi 1982, Longobardi 1991) do not appear to equally concern Ibero-Romance (and even colloquial varieties of some Italian speakers)?

\footnotetext{
vac (1994), Acquaviva (1997), Martins (2000), Herburger (2001), Martín-González (2002), Giannakidou (2002), Zeijlstra (2004), Ovalle and Guerzoni (2004), Watanabe (2004), Guerzoni (2006), De Swart (2010), Penka (2011), among literally innumerable others, along with Bernini and Ramat's (1992), Haegeman (1995), Zanuttini's (1997), and Rowlett's (1998) now classic reference books. Some of these works have relied on ideas I first exposed in the 1987 presentation, but all such scholars have eventually pursued these topics to an extent and empirical detail incomparable with those attained in my original talk.

9 Longobardi (1987) had originally been planned as an appendix to Longobardi (1991), precisely to explain the puzzling differences between Standard Italian and Spanish embedded N-words treated in section 9. below.

10 Cf. Penka and Zeijlstra (2010) for a brief but perspicuous overview of the unsettled status of (3). As for (4), though so relevant for the theory of covert dependencies, it has been insightfully addressed, to my knowledge, only in Español-Echevarría (1994).
} 
The basic answer in Longobardi $(1987,2003 a)$ was that there exist three core dimensions of parametrisation, respectively meant to define

whether the morpheme understood as simple propositional negative connective (like e.g. Modern English not) superficially occurs pre- or post-Infl, i.e. precedes or follows finite auxiliaries or verbs ${ }^{11}$ (Italian, Spanish, Catalan etc. vs. French, Gallo-Italic dialects of Northwestern Italy, such as Piedmontese and Lombard among others: now see Zanuttini 1997 for an impressively wide investigation);

whether sentential negative morphemes are indeed normally interpreted as actual propositional connectives (e.g. It. non ${ }^{12}$ ), or just function as mere scope markers for other negative items (e.g. Fr. ne), or are potentially ambiguous between the two (e.g. Cat. no, Rum. $n u$ ). The distinction can be understood in terms of a feature 'independent negative operator (henceforth \pm NOT)';

(6) how negative phrases binding quantificational variables, like e.g. Italian nessuno, niente, mai, Spanish nadie, nada, nunca, French rien, personne, jamais etc. (N-words in Laka's 1990 terms), are lexically specified with respect to two features: +ANY, basically characterising 'negative polarity items'(Linebarger's 1980 NPIs), and indeed +NOT above, characterising ‘independent negative quantifiers' (Español-Echevarría’s 1994 NQs).

The three proposals were meant to function systemically, each amending and complementing the empirical scope of the other, minimising redundancy. Since 1987, such ideas have been explored by several scholars: e.g. the relevance of pre- and post-Auxiliary position of negation has been supported by Haegeman and Zanuttini (1996) and Zanuttini's (1997) dialectological survey; the double specification of Romance N-words as NPIs and as NQs has indeed been brought to deepest consequences by Español-Echevarría (1994), possibly the most original and innovative development in the debate ${ }^{13}$; the idea of the interpreted vs. uninterpreted status of non, no, ne, nu etc. has been adopted in Zeijlstra (2004, 2008), Biberauer and Zeijlstra (2012. However, not only were these three ideas completely new at the time, but, more importantly, they have never been put to work together in a consistent system since.

\section{FEATURE SPECIFICATIONS}

As an operational rule (as well as a plausible acquisition cue from positive evidence), let me suggest (8):

\footnotetext{
11 Such two positions are frequently described in the literature as pre- and post-verbal (e.g. Zeijlstra 2008, passim), somewhat obscuring the belonging of the phenomenon in the functional structure of the sentence. Adverbial N-words, such as mai'n/ever' or mica'indeed not, not at all (under the opposite presupposition)', clearly show, instead, that the first auxiliary is the relevant positional indicator.

12 Except for some special cases, like e.g. in comparatives.

13 Also cf. Vallduví (1994), Espinal (2000), Herburger (2001), among others.
} 
an item is lexically specified +NOT if and only if it may be used as a bearer of negative meaning by itself, e.g. as a negative answer to a question ${ }^{14}$ (or other absolute instances) or as the only negative operator of a negated sentence

An expected correlating property will be the possibility of providing a 'double negation' reading in the scope of another +NOT item.

Given (8), it turns out first that the words for 'nobody' (or 'nothing' and the like) of all the languages below are [+NOT]; then, in turn, that, of pre-Infl sentential negative particles, Italian non, Spanish no, Catalan no (cf. Solà 1992) and Rumanian $n u$ will be [+NOT] (the latter two with some provisos, for which cf. below), while French $n e$ will be $[-\mathrm{NOT}]^{15}$ :

(8) a. Chi è venuto? Nessuno

b.

(9) a. Quien vino? Nadie

b.

(10) a. Quin ha vingut? Ningú

b.

\section{Italian}

Who came? Nobody

Gianni non è venuto

G. did not come

Who came? Nobody

Juan no vino

J. did not come

Catalan

Who came? Nobody

Joan no ha vingut

J. did not come

14 This test, used in Longobardi (1987), Zanuttini (1991), Haspelmath (1997) has been criticised in Giannakidou (2002), mostly because occasionally extendible to some colloquial NPIs. The critique is unconvincing, at least since other absolute expressions, like exclamations, enumerations sharply single out [+NOT] items.

15 Also cf. Martins $(2000,196)$. 
(11) a. Cine a venit? Nimeni

b.

(12) a. Qui est venu? Personne

b.*$$
\text { * }
$$

Rumanian

Who came? Nobody

Ion $n u$ a venit

I. did not come

French

'Who came? Nobody'

Jean $n$ 'est venu

J. $N E$ has come

French pas, instead, can be argued to be [+NOT] on the grounds of e.g. (14):

In sum, the feature +NOT may both apply to sentential particles, functioning as a propositional connective, and combine with restricted variables, so appearing on determiners and adverbs. In either case, the feature +NOT is taken to mean the logical connective ' $\neg$ '. The determiners or adverbs in question can then be taken to mean either of the two logically equivalent possibilities: ' $\forall \neg$ ' and ' $\neg \exists$ '. The question will be addressed later.

Natural languages notoriously exhibit another subclass of items interpreted as existential variables which need be negatively closed (Linebarger's 1980 NPIs), which can do so non-locally, i.e. by being in the scope of a distinct negative word. In Longobardi (1987), NPIs were characterised by the feature +ANY, taken to obey Linebarger's (1980) Immediate Scope Constraint, ISC:

a [+ANY] existential operator must be in the immediate scope of a negative operator.

More precisely, an NPI is licensed only in the immediate scope of (often c-commanded by ${ }^{16}$ ) a certain class of elements, at the core of which one always finds independent negative operators ${ }^{17}$.

Then, as an operational rule to assign + ANY, let me propose (16):

\footnotetext{
16 A strategy fully complementary to c-command seems to be at work in languages such as Korean (Sells and Kim 2006), suggesting a generalisation of the Immediate Scope Constraint. I will not attempt parametric hypotheses about such differences here.

17 The whole class of licensers (including some modal verbs, interrogatives and monotone decreasing quantifiers) can perhaps be defined as 'non-veridical' operators (Giannakidou, 1998). Also cf. Martins (2000), and especially Penka and Zeijlstra (2010) for an overview of the issues in defining licensers of NPIs.
} 
the lexical head of a phrase is assigned +ANY if and only if that phrase is interpreted as an existentially bound variable in the immediate scope of a distinct negative operator and nowhere els $\mathrm{e}^{18}$.

Notice, first, that by definition, propositional negations, like Sp. no, It. non, French pas (both formal, occurring with $n e$, and colloquial, without $n e$ ), as well as English not, must fail to qualify for +ANY. For, they do not instantiate a variable at all. Given the Full Interpretation Principle, this correctly predicts that there will be no other interpretation than 'double negation' in (17):

(16) a. Nessuno non è venuto

$\begin{array}{lc}\text { b. } & \text { 'Nobody did not come' } \\ \text { c. Nadie no vino } \\ \text { 'Nobody did not come' } \\ \text { Personne (n')est pas venu } \\ \text { 'Nobody did not come' }\end{array}$

For Catalan no, French $n e$ and Rumanian $n u$, again, some qualifications are needed (cf. (34) in section 6. below).

As for quantificational variables, lack of positive values for either feature, i.e. [-NOT, -ANY], is probably the default choice, represented by all non-negative items of a language, including e.g. quantifiers like e.g. some(-body, -thing.... ${ }^{19}$.

Instead, lexical items like English no(-body, -thing etc.) and any(-body, -thing etc.: abstracting away from so-called 'free-choice' any) are prototypically [+NOT, -ANY] and [-NOT, +ANY], respectively:

18 I.e. unless it has been found as existentially quantified also without the scope of a non-veridical operator.

19 The negative values of the features will be attributed no ontological value, i.e. they only mean absence of the feature and are used for notational convenience. 
(17) a. Who arrived? Nobody

(18) a. Nobody said anything b.

Who arrived? *Anybody

By parity of reasoning, one must conclude that the literary Italian alcuno series ${ }^{20}$, as well as items like più in the meaning 'any longer' or granché 'much', is also consistently specified [-NOT, +ANY]:

(19) a. Nessuno ha detto alcunché

Nobody said anything

b. Che è successo? *Alcunché

(vs. OK Niente 'Nothing')

What happened? Anything

\section{A MAJOR TYPOLOGICAL GENERALISATION}

Now consider Standard Italian (henceforth identified for our purposes with the variety described in Rizzi 1982 and Longobardi 1991) nessuno, niente etc. and Spanish nadie, nada more closely; according to the tests, they turn out to be specified not only for [+NOT] (cf. (9)a.-(10)a.-(11)a.), but also for [+ANY]:

(20) a. Niente può impressionare nessuno, qui

b.

Nada puede impresionar a nadie, aquí

'Nothing can impress anybody, here'

(21) a. Nessuno dirà niente

b.

Nadie decirá nada

'Nobody will say anything'

20 Cf. Longobardi (1988), Crisma (2012) for morphosyntactic details. 
The first step of Longobardi's (1987) hypothesis was that such words are lexically ambiguous between the specification of, say, anybody [-NOT, +ANY] and that of nobody [+NOT, -ANY]. This disjunctive, free-choice analysis, predicts that nessuno, niente or nadie, nada should have the sum of the distributions of anybody, anything and nobody, nothing; a first apparent objection against it is raised by (23)a., which shows that they cannot just meet the conditions on English no alone:

(22) a.* Ho visto nessuno/He visto a nadie

I-have seen nobody

b.

Non ho visto nessuno/No he visto a nadie

Not I-have seen anybody

'I saw nobody'

This objection was circumvented in Longobardi (1987) through the forerunner of what could now be a topological mapping (Longobardi 2005b, Hinzen and Sheehan 2011) principle:

\begin{abstract}
Fundamental Asymmetry Hypothesis (FAH):
the +NOT value can always be interpreted (semantically activated) in pre-Infl position (of the sentence over which it is meant to have scope) in all Romance languages. In post-Infl position (of the sentence over which it is meant to have scope) it is interpreted only if the simple propositional negation of the language is itself post-Infl (cf. parameter (5)).
\end{abstract}

Therefore, in languages like Italian, Spanish, Catalan, Rumanian, given the pre-Infl surfacing of the simple negation (cf. (9)b., (10)b., (11)b., (12)b.) the +NOT feature of, say, nessuno, nadie, ningú, nimeni etc. in post-Infl position would be necessarily insufficient to achieve sentential scope, so that the negative phrase could only be interpreted by means of its +ANY feature. In pre-Infl position, instead, the +NOT feature could be interpreted, correctly yielding, among other things, the 'double negation' effects of Italian and Spanish (17)a. and b. above, as well as contrasts like (25)-(26) in Italian ${ }^{21}$ :

\footnotetext{
21 Double negation often requires contrastive stress on either of the two [+NOT] items, chosen according to the presuppositions. Stressing may affect the simple sentential negative morpheme, as in ii., which is quite possible, at least in echo-contexts:

NESSUNO non fa qualche errore

Nessuno NON fa qualche errore

'Nobody doesn't make some mistake'

Note that this requirement, however, is by no means general, not applying at all, for instance, in (26)b. Cf. section 10. below for more detail.
} 
(24) a. A nessuno niente fa paura

To nobody nothing makes fear

'Nobody fears nothing'

b.

A nessuno fa paura niente

To nobody makes fear nothing

'Nobody fears anything'

(25) a. Mica viene

Not-indeed comes
' $\mathrm{S} / \mathrm{He}$ is not coming'

b.

Mica non viene

'It is not the case that $\mathrm{s} / \mathrm{he}$ is not coming'

c.

Non viene mica

' $\mathrm{S} / \mathrm{He}$ is not coming'

The proposal in (24) was central in Longobardi (1987): it has brought to light a crucial feature of the Romance negation diasystem, establishing an implication between having a post-Infl sentential negation and having post-Infl $\mathrm{N}$-words not required to cooccur with negation.

First, (24) predicts that an N-word with a +NOT feature may occur in pre-Infl position without any further negative marker, in several varieties as diverse as Italian, Spanish, Gallo-Italic dialects such as Piedmontese (data from Settimo Torinese, kindly provided by C. Bracco), colloquial French (and apparently Portuguese):

(26) a. Nessuno è venuto

b. Nadie vino

c. Gnun a l'è mnuit

d. Personne est venu
Italian Spanish

Settimo T.

Col. French

'Nobody came'

Second, the Romance languages in which the basic propositional negation occurs in pre-Infl position (e.g. Italian, Spanish, Catalan, Rumanian, as well as Portuguese) are correctly predicted to be all 
identical in requiring the overt appearance of the same morpheme also for negative quantifiers to occur in post-Infl position (crucially including all types of postverbal subject positions):

(27) a.* E' venuto nessuno

b. *

Vino nadie

c. *

Ha vingut ningú

d. *

A venit nimeni

Came nobody

'Nobody came'

It is a consequence precisely of principle (24) that in such cases they must resort to a structure which satisfies, but also crucially triggers, a + ANY feature in their lexical representation:

(28) a. Non è venuto nessuno

b.

No vino nadie

c.

No ha vingut ningú

d.

$\mathrm{Nu}$ a venit nimeni

Not came nobody

'Nobody came'

This is in contrast to (both colloquial and formal) French and Gallo-Italic dialects (now see Zanuttini 2001, 522 for a fuller overview), but also English of course, which all display a post-Infl propositional negation:

(29) a. Il (n') est venu personne

b. A l'è mnuje gnun

\section{French}

'There (ne) came nobody'

Settimo T.

$\mathrm{Cl} 3 \mathrm{sg}$ is come-CLthere nobody

'Nobody came' 
(30) a. Il (n') est pas venu

b. A l'è nen mnuit

\section{French}

He is not come

Settimo T.

He is not come

'He did not come'

\section{RUMANIAN AND CATALAN}

However, this correct parametrisation is insufficient to account for the pre-Infl behaviour of N-words in Rumanian, formal French and modern Catalan, which require a pre-Infl negative morpheme ( $n u$, $n e$, and no, respectively) not entailing 'double-negation' reading:

(31) a.* Nimeni a venit

b.

(32) a.* Personne est venu

b.

\author{
Rumanian \\ Nimeni nu a venit \\ 'Nobody came' \\ (formal) French \\ Personne n'est venu \\ 'Nobody came'
}

This generalisation leads one to conclude that in this class of languages, crosscutting the previous distinction between pre- and post-Infl negation, something like (34) is a theorem of their grammar:

(33) The sentential scope of an N-word must always be readable off an overt separate negative morpheme (whether the latter is identical with the simple clausal negation or not)

To derive (34), one must assume that in some languages certain instances of sentential negative particles will not be interpreted as negative connectives, i.e. precisely the parametrisation in (6) (cf. the assignment of \pm NOT in section 4.).

Modern Catalan seems to exhibit some surface optionality of the marker, as if the formal and colloquial 
varieties of French were collapsed, which is difficult to reconcile with a tight conception of narrow syntax:

Ningú (no) ha vingut

'Nobody came'

However, it might perhaps be reduced to classical grammatical competition (Kroch 1989) resulting from original dialect variation ${ }^{22}$.

In sum, one may characterise Romance first with a typological split that divides Gallo-Romance (including Occitan, cf. below, and Gallo-Italic) from everything else; then, in both groups we find varieties which use a special morpheme (typically formal French) or the normal clausal negation (Daco-Romance, Occitan, toward which has been drifting Catalan) simply as a negative scope marker, and others which do not.

\title{
7. FURTHER CONSEQUENCES OF THE FUNDAMENTAL ASYMMETRY
}

Next, consider that the presence of a + ANY feature on Italian or Spanish N-words seems almost naturally forced by (24) in conjunction with some lexical or paradigmatic Economy principle. Suppose

\author{
Negative Anti-Synonymy: \\ languages do not specialise two different sets of [+NOT] N-words just for pre-Infl and post-Infl positions
}

Then, the ungrammaticality of (23) or (28), imposed by (24) to languages with pre-Infl negation, requires the grammaticality of (29), which witnesses the existence of a [+ANY] specification, and consequently the equal grammaticality of 'negative concord' examples (21)-(22). The typological prediction is correct: the equivalents of (21)-(22) are grammatical in all varieties with simple preInfl negation, i.e. in all of them N-words are also specified [+ANY]. But in languages with postInfl negation this system predicts variety (crosslinguistically, or even crosslexically) to be found: traditional 'negative concord' and 'double negation' languages/constructions. This is precisely the case, opposing e.g. English to Romance. For, French N-words can cooccur with each other without necessarily having 'double negation' meaning:

22 M. Español-Echevarría (p.c.) suggests that, beside some influence of the lexical choice of the negative quantifier, the presence of no, seems more salient in Northern varieties of Catalan, a fact compatible with a situation of minimally different competing grammars. 
(36) a. Rien ne peut impressionner personne, ici

'Nothing can impress anybody, here'

'Nothing can impress nobody, here'

b.

Personne n'a rien fait

'Nobody did anything'

'Nobody did nothing'

In Standard English such sentences, with nobody/nothing, only receive 'double negation' interpretation; in Spanish and Italian, with nadie/nessuno, only 'negative concord' reading ((21)-(22)), owing, obviously, to (24)).

The ambiguity of French, here, as opposed to Italian/Spanish, is due to its being a post-Infl-negation language. But, given that both English and French are post-Infl negation languages, the contrast above between ambiguous French personne (or rien and the like) and non-ambiguous English no(body etc.) can be reduced to the hypothesis that French N-words are specified [+NOT, +ANY], as in other Romance languages, while English no is just [+NOT]. Actually, no instance of no(body) in Standard English need ever rely on, and thus ever provides evidence for, a + ANY specification (cf. the rules in section 4. above) $)^{23}$.

An important theorem of all this approach is, then, (38):

So called 'double negation' languages are the epiphenomenal manifestation of post-Infl negation combined with unambiguous [+NOT, -ANY] N-words

The semantic ambiguity of the cooccurrence of two French negative quantifiers (between 'negative concord' and 'double negation', the latter presumably in most cases disambiguated through stress, cf. (37)), can appear in other post-Infl negation languages as well. So beside (37)b one finds in some Gallo-Italic dialects:

Gnun a l'a fait gnente

Settimo T.

'Nobody did anything'

'Nobody did nothing'

23 French instead instantiates even further constructions where [+NOT, +ANY] is crucially used ((72) below). 
Notice that the same ambiguity is predicted for Rumanian, though for different reasons, since the latter is a pre-Infl-negation language, like Italian and Spanish. Recall that pre-Infl $n u$ in Rumanian is ambiguous between +NOT and-NOT; therefore, structures like (40) below must anyway be expected to be segmentally ambiguous between 'double negation' (with [+NOT] $n u$ licensing nimic and at the same time serving as a negative marker for nimeni) and 'negative concord' reading (with [-NOT] $n u$ just serving as a scope marker and nimeni licensing nimic):

Nimeni nu a facut nimic

\author{
'Nobody did anything' \\ 'Nobody did nothing'
}

The prediction is borne out, as now keenly noticed in both Giannakidou (2002) and Penka and Zeijlstra (2010), and can correctly be replicated for Catalan (M. Español-Echevarría, p.c.):

Ningú no ha fet res

\author{
'Nobody did anything' \\ 'Nobody did nothing'
}

The conclusion anyway confirms that, throughout Romance, the same N-words can bear [+NOT] and [+ANY].

\title{
8. CONDITIONS ON SCOPE ASSIGNMENT
}

Yet, a subtler but theoretically consequential distinction must be made: the analysis of $\mathrm{N}$-words as ambiguous, whether accurate or not for Ibero-Romance (and colloquial varieties of Italian: cf. below), is anyway insufficient for Standard Italian. In such a language, in more complex environments, nessuno, niente do not have the sum of the distributions of any-body,-thing and no-body,-thing. For, nessuno, niente etc. display well-known asymmetries between pre- and post-verbal subjects (more generally between pre- and post-Infl positions): their behaviour in pre-Infl position assimilates them precisely to no-items and opposes them to any-items. Thus, while (42)a. and b. are semantically rather interchangeable, both corresponding in meaning to the same English translation (with anything), this is no longer the case with (43), as originally pointed out by Rizzi (1982); in (43)a. embedded preverbal niente may only have the meaning of its translation (i.e. 'nothing'), with 'double negation' reading, and cannot display 'concord' with matrix non, as is instead the case for alcunché ('anything'): 
(41) a. Non pretendo che faccia niente b.

Non pretendo che faccia alcunché

'I do not require that he do anything'

(42) a. Non pretendo che niente possa fargli cambiare idea

'I do not require that nothing can change his mind'

b.

Non pretendo che alcunché possa fargli cambiare idea

'I do not require that anything can change his mind'

Thus, N-words of Standard Italian cannot achieve wide-scope negative 'concord' (i.e. with an upper clause non) from a pre-Infl position, recalling precisely the (somewhat different, cf. below) phenomenon first observed for French personne by Kayne (1981), who reduced it to an effect of the Nominative Island Condition (NIC, later subsumed under Chomsky's 1981 Empty Category Principle, ECP) ${ }^{24}$.

Furthermore, as later pointed out in Longobardi (1991), scope assignment over a matrix sentence to nessuno/niente-type items, unlike Italian alcuno items and English any, also obeys some classical island constraints:

(43) a.?* Non fa questo lavoro [per ottenere niente]

b.

Non fa questo lavoro per ottenere alcunché

intended meaning: 'He doesn't do this job in order to obtain anything'

(44)

* [Dire niente] può fargli cambiare idea

Saying nothing can change his mind

intended meaning: 'Nothing is such that saying it can change his mind'

24 The sentence without upper clause non is also ungrammatical with wide-scope negation and can only be understood as a positive assertion: Pretendo che niente possa fargli cambiare idea

'I require that nothing can change his mind'

here the NIC/ECP violation is likely to add up to the uninterpretability of post-Infl +NOT descending from (24), already sufficient to rule ungrammatical the correspondent of (42)a. without non. 
a. ${ }^{*}$ Non mi aspetto che [dire niente] possa servirci

b.

c.
Non mi aspetto che [dire alcunché] possa servirci

Non mi aspetto che possa servirci [dire niente]

'I do not expect that saying anything can be helpful'

Therefore, clearly, Italian nessuno, niente cannot limit themselves to just satisfying the conditions on English any.

For these reasons, Longobardi (1987, 2003a) suggested that the Standard Italian nessuno, niente series is not lexically ambiguous (homophonous), but rather obeys conditions on NQs and on NPIs at the same time: thus, such words must be conjunctively specified [+NOT, $+\mathrm{ANY}$ ], the expected fourth logical possibility. Their behaviour can then follow from the following crosslinguistic proposal:

items lexically marked [+NOT] (however the feature ends up interpreted, cf. (24) above) with non-local scope obey classical island constraints as well as some version of Chomsky's (1981) ECP, like only+XP phrases and other wide scope quantifiers (Kayne 1981, Rizzi 1982, Longobardi 1991) ${ }^{25}$;

In more technical terms we can now state:

$$
\mathrm{ECP} / \text { Islands }=\text { conditions on Agree (all Probe-Goal relations) }
$$

Non-local scope of + NOT always involves Agree at some point

Italian N-words in structures like (43), (44) and (46) could in principle resort to their feature +ANY in order to be connected to the matrix non. But since they are anyway lexically marked also by the syntactic +NOT feature, though semantically inactive with respect to matrix negative scope (according to (24)), they should always observe ECP (descriptively understood as a ban on longdistance dependencies from all pre-Infl positions ${ }^{26}$ ) and island constraints. A fortiori, this would be

\footnotetext{
25 This amounts to saying that wide-scope +NOT always establishes a syntactic dependency with an upper +NOT and/or a scope position (a Probe-Goal relation, in current terms), while +ANY, which just stands for an existential quantifier in the semantic scope of another appropriate operator, does not (cf. Giannakidou 2002: (141)a. and b.).

26 Some remarks are in order about the nature of the so-called ECP. It must be noted that in Italian not only subject N-words are restricted to local scope, but also any other pre-Infl N-word, typically phrases fronted under focusing:

i. $\quad$ a. Non pretendo che NESSUNO tu veda

I do not require that NOBODY you see

b. $\quad$ Non pretendo che a NESSUNO tu riveli questo

I do not require that to NOBODY you reveal this
} 
true in (45), where +NOT should even be interpreted.

Examples such as (44)-(45)-(46), i.e. of the type discussed in Longobardi (1991), are particularly important for the formulation of (47) and the consequent theory of covert long-distance dependencies. For, if we limit ourselves to sentences such as (43) (and the analogous examples originally brought to light by Rizzi 1982), it could still be objected that the constraint on N-words here is just of a functional nature: +NOT, wherever interpretable (i.e. with local scope), would override +ANY (i.e. wide-scope negative concord). Instead, (44)-(45)-(46) show that this is not sufficient.

Now, given the conjunction of +NOT and $+\mathrm{ANY}$ on Italian N-words, one may wonder how it is possible for the latter feature to be licensed in normal pre-Infl examples with local scope, such as (9) a., (27)a. or (43)a.

The question arises because of the impossibility of NPIs in (20)b. or just in preverbal subject position with a local negation:

(49) * Alcunché non la fermerà

Anything will not stop her

Therefore, it was proposed in Longobardi (1987) that:

The negative operator $+\mathrm{NOT}$, if and only if interpreted, qualifies as able to internally satisfy a +ANY feature conjoined with it on the same item, which thus automatically meets Linebarger's (1980) Immediate Scope Constraint ${ }^{27}$.

In other words, the interpretation of nessuno/niente etc. results from their featural composition under the Full Interpretation Principle: the combined specification [+NOT, +ANY] straightforwardly translates to ' $\neg \exists$ '.

Non pretendo che in NESSUN caso sia arrestato

I do not require that under NO circumstance he be arrested

This fact apparently refutes accounts based on notions such as 'Nominative' or 'subject' or 'agreeing with T'. Plausibly, it could support an approach to ECP as 'criterial freezing' (Rizzi 1991, Rizzi and Shlonsky 2006), where reaching a licit position of negative scope could make a [+NOT] item satisfy its interpretive requirements (cf. Haegeman and Zanuttini 1991), preventing the establishment of further dependencies. This is possible if such a criterial freezing is understood as constraining not only overt movement, but also covert relations. On the contrary, scope reconstruction of an $\mathrm{N}$-word from a criterial position seems possible. Thus, ii. is ambiguous between wide and narrow scope:

ii. NESSUNO pretendo che tu veda!

'I require that you not see anybody'

'I do not require that you see anybody'

27 Conceivably, this should automatically follow from the configuration being one of morphological c-command: in several Indo-European languages a +ANY item shifts to a +NOT one by the addition of an obvious negative N(E) prefix (e.g. ever/never, Latin ullus/nullus 'any'/'no' etc., or the widespread Slavic doublets: Progovac 1995, Giannakidou 2002), thus the linear order could perhaps instantiate word-internal prominence of +NOT in the antisymmetric spirit of Kayne (1994). 
When +NOT cannot be interpreted in the local environment (because of (24)), it will have to establish a CHAIN (Chomsky 1986: a single interpretative object) with a c-commanding interpretable [+NOT] item, and the two positions of the CHAIN will act as a single negative operator scoping over + ANY, no less than an expletive-associate CHAIN behaves as a single argument. If CHAIN formation involves Agree, condition (49) (i.e. (47)) will now follow by definition.

English nobody/nothing, which are only specified [+NOT] (i.e. lack [+ANY], cf. sections 4. and 7.) cannot be interpreted compositionally as such: I will tentatively suppose that they require a default operator to bind the variable they provide, and this cannot be inserted into the scope of the feature +NOT already part of these lexical items, because any such operation would violate the Lexical Integrity Hypothesis. Therefore, the only possibility for obtaining their meaning as negative quantifiers is introducing a default universal operator scoping over + NOT, i.e. a logical translation ' $\forall \neg$ '. At the same time, as a default operator rather than a lexical determiner it should be unable to achieve scope over other logical elements, in parallel to default existentials (Carlson 1977). Notice now that the intervention of a universal quantifier seems to fatally interrupt a negative CHAIN of the type proposed above, as exemplified by the following pattern:

(51) a. Non voglio che Gianni dica niente

I don't want Gianni to say anything

b.

Non voglio che tutti dicano questo

I don't want all to say this

c. *

Non voglio che tutti dicano niente

I don't want all to say anything

I tentatively propose that the CHAIN is ruled out in these cases by the contradictory scope requirements imposed to the same semantic object (the negative operator) by its two positions with respect to the universal quantifier. Along these lines, one can correctly conclude that Standard English N-words can never enter a CHAIN and provide 'negative concord' effects.

Anyway, the combination of (24) with the largely independent requirements (47) and (51) makes it possible to explain the peculiar behaviour of Italian negative items.

\section{ITALIAN AND SPANISH}

Recall that +NOT by itself was shown to have the peculiarity that on certain sentential negative particles it may freely appear or not: this provides for the ambiguity of Catalan no and Rumanian $n u$. In the conceptually 'perfect' system we could expect also some N-word to be ambiguous between 
+NOT and -NOT, in particular in cooccurrence with a +ANY feature ${ }^{28}$.

Consider Spanish nadie, nada etc. (but also nessuno/niente in the colloquial varieties of some other Italian speakers): these items share with Standard Italian the paradigms (9)a.-(10)a., witnessing a specification [+NOT], and (21)-(22) witnessing [+ANY]; but, while Standard French and Standard Italian (thereby referring again to the varieties described in Kayne 1981, Rizzi 1982, Longobardi 1991) exhibit ECP and island effects on wide scope of negative elements like personne and nessuno, the Spanish ones appear not to be equally subject to these conditions:

(52) a. Non pretendo che nessuno venga

Stand. Italian: unambiguous

'I do not require that nobody come'

b. No exigo que nadie venga

Spanish: ambiguous

'I do not require that anybody come'

'I do not require that nobody come'

The contrast predictably disappears for postverbal subjects, whose position respects ECP:

(53) a. Non pretendo che venga nessuno

'I do not require that anybody come'

b.

No exigo que venga nadie

'I do not require that anybody come'

The contrast in (53) cannot be imputed to a difference in the constraints themselves, since in the grammar of the same Spanish speakers such constraints are independently active on similar constructions, in parallel to Italian: they hold for 'hidden' negative quantifiers, like only-phrases of the type discussed in Longobardi (1991), and probably WH-in situ (Jaeggli 1984).

Thus, nadie etc. seem to display at least the sum of the distributions of English no and any (providing precisely for the ambiguity in (53)b.). Longobardi (1987) concluded from this that, since, unlike their Italian counterparts, they are lexically ambiguous between [+NOT, -ANY] and [-NOT, +ANY], i.e.

28 It is perhaps less likely that one may find a case of ambiguity between [+NOT] (in whatever combination) and [-NOT, -ANY], because this would mean that the same lexical item would optionally be a full negative operator and a completely non-negative expression, generating e.g. ambiguities between a'nothing' and a 'something' reading. A famous example of ambiguity in this sense, though one used as a literary expedient, is provided by Homer's usage of OṽTıc (morphologically a still very recognisable case of $\neg \exists$ ) as a NQ and a proper name in । $366 \mathrm{ff}$. 
they can be disjunctively, rather than conjunctively, specified for +NOT and +ANY: each of their occurrences can be interpreted with either +NOT or +ANY, circumventing the constraints following from the opposite specification.

The proposal can now be supported and refined through the highly significant results obtained by Español-Echevarría (1994, 3ff). He starts from the generalisation that adverbs meaning 'almost' or 'absolutely' can hardly modify existential quantifiers ('almost everyone' vs. *'almost someone') and, correspondingly seem to naturally occur with straight negative quantifiers, though not with unambiguous NPIs:

(54) a. I saw almost nobody

b. *

I did not see almost anybody ${ }^{29}$

(55) a. Non ho visto quasi niente

I saw almost nothing

b. *

Non ho visto quasi alcunché

I not saw almost anything

thus, while agreeing on the hypothesis of systematic ambiguity for Spanish N-words, he argues independently that, when modified by casi 'almost', they must fail to qualify just as NPIs in the scope of a higher negation, and points out (p. 4) contrasts in island violations which precisely support the conclusion that when introduced by casi such items are like the Standard Italian ones, i.e., in our present terms, must remain +NOT:

(56) a. No he venido porque quiera ver a nadie

'I did not come because I wanted to see anyone'

b. *

No he venido porque quiera ver a casi nadie

'I did not come because I wanted to see almost anyone'

The same is true for ECP violations:

29 Sells and Kim's (2006) (28)a., perhaps ultimately reducible to the Immediate Scope Constraint (cf. Giannakidou 2002). 
At this point, the unexpected subtle difference between Spanish and Standard Italian, which could have undermined the generalisations on covert dependencies obtained by Rizzi (1982) and Longobardi (1991) in the wake of Kayne (1981), is explained away in a straightforward fashion.

Notice that (57)a also confirms that Italian N-words can be [+NOT] even when they surface in contexts of apparent concord, the $\neg \exists$ apparently and plausibly being able to semantically satisfy the requirement on quasi. Again, they are able to satisfy the requirements on $+\mathrm{NOT}$ and $+\mathrm{ANY}$ at the same time.

Actually, one may theoretically wonder if the Spanish disjunction between +NOT and +ANY is to be understood as exclusive or inclusive (i.e. also admitting of the conjunctive option [+NOT, +ANY], as in Standard Italian). The latter alternative seems conceptually more plausible, given that no intrinsic incompatibility appears to exist between the two features, therefore their mutual exclusion would have to be stipulated.

Now, since Spanish perfectly admits the equivalent of Italian (56)a, the inclusive interpretation of the feature disjunction is supported empirically:

(58) a. No he visto casi nada

I saw almost nothing

In this respect, the distribution of Spanish N-words is in fact more than just the sum of those of English no and any, requiring precisely [+NOT, +ANY]. But notice, then, that given again (51), [+NOT, +ANY] is empirically indistinguishable from [+NOT, -ANY] in pre-Infl position: indeed, the latter specification becomes redundant for Spanish. As envisaged at the beginning of this section, Spanish $\mathrm{N}$-words could actually be regarded just as ambiguous between the [+NOT] and [-NOT] specifications in the context of [+ANY], the latter now a permanent feature of all Romance $\mathrm{N}$-words.

\section{PRE-INFL POSITIONS}

A final prediction concerns the status of two pre-Infl N-words: given that the ECP constraints on +NOT hold only for long distance relations (wide scope), an N-word locally licensed by another one should be possible also in pre-Infl position, leading to the disappearance of significant contrast with Ibero-Romance. The expectation seems to be borne out, though blurred by various idiosyncratic 
complications.

We saw that some pairs of pre-Infl N-words in Italian may give rise to double negation, as e.g. in (25), though with some marked informational and prosodic structure. In (25) a concord reading seems to be disfavoured. Indeed, even in Spanish (or Catalan), where the feature +NOT could be lexically absent from the second $\mathrm{N}$-word, leaving it to be licensed just as +ANY by the first, i.e. under negative concord, this is hardly the case:

(59) * A ninguno de nosotros nada nos/le da miedo

To none of us nothing us/him gives fear

(60) ?? A cap de nosaltres res no ens fa por.

To none of us nothing us makes fear

Such examples are not fully acceptable, even with the double-negation reading, and definitely fail to receive a concord one.

As keenly pointed out by M. Español (p.c.), this should be due to some constraint on the local licensing of the $\mathrm{N}$-words as polarity items, since such structures return grammatical with the Ibero-Romance concord interpretation in the scope of a higher negation:

(61) No es cierto que a ninguno de nosotros nada nos dé miedo

Not is certain that to none of us nothing us gives fear

'It is not certain that none of us fears anything'

(62)

No és veritat que a cap de nosaltres res no ens faci por

Not is truth that to none of us nothing not us makes fear

'It is not true that any of us fears anything'

This result is not very surprising; even in Italian the correspondent of (25) with the unambiguous NPI alcunché replacing niente is hardly grammatical, and sharply contrasts with the variants in which alcunché/niente are postverbal: 
(63) a. ?*A NESSUNO di noi alcunché fa paura

To none of us anything makes fear

'None of us fears anything' b.

A NESSUNO di noi fa paura alcunché/niente

To none of us makes fear anything/nothing

'None of us fears anything'

Therefore, at least the impossibility of concord in (60)-(61) appears to be amenable to some further condition on + ANY, at work in Italian as well.

Instead, as a matter of fact, local 'negative concord', is possible for a pre-Infl N-word in both Italian and Ibero-Romance in some other cases, when some (unclear) Superiority-like constraint is met; direct arguments (subject and direct object) rather easily license oblique ones under concord, though not viceversa:

(64) a. Niente a nessuno devi dire!

'Nothing to anybody must you say!'

b.??

A nessuno niente devi dire!

'To nobody nothing must you say!'

(65) a. ¡Nada a nadie tienes que decir!

'Nothing to anybody must you say!'

b.??

¡A nadie nada tienes que decir!

'To nobody nothing must you say!'

(66) a. ¡Res a ningú has de dir!

'Nothing to anybody must you say!'

b.??

¡A ningú res has de dir!

'To nobody nothing must you say!

It is also remarkable, though as yet unexplained, that certain $\mathrm{N}$-adverbs such as mai most easily enter these licensing relations (both in Italian and Ibero-Romance): 
The whole set of phenomena is poorly understood, but sufficient to attempt two conclusions: even Italian N-words can sometimes display concord in pre-Infl position through their [+ANY] feature, and the contexts in which they fail to do so largely correspond to those in which Ibero-Romance N-words fail as well. This is consistent with the expectation that the presence or absence of [+NOT] should produce no observable contrasts between the two varieties in local (non-wide-scope) environments.

These data confirm the hypothesis that, in cases of 'concord', Italian N-words must comply with some conditions on $+\mathrm{ANY}$, not just on $+\mathrm{NOT}^{30}$.

\section{SOME FRENCH}

Now consider French again, in particular the formal variety requiring $n e$. Ne has the same distribution as It. non, Sp. no, Cat. no, Rum. nu, but, according to the tests in section 4, turned out steadily [-NOT]; as said, pas, has fixed ${ }^{31}$ post-Infl distribution and seems to be [+NOT]:

(68) a. Jean n'est pas venu

$$
\text { 'J. did not come' }
$$

b.

Personne n'est pas venu

'Nobody did not come'

A fortiori, the conclusion will be true for post-Infl basic sentential negations in varieties which lack the obligatory scope marker, like colloquial French, many Gallo-Italic dialects, or even for English not.

$\mathrm{N}$-words such as personne, rien, aucun etc. were argued to be [+NOT] (cf. (13) $)^{32}$, but also [+ANY] (cf. (37)), like other corresponding Romance items: now are they disjunctively specified for + NOT or

\footnotetext{
30 That they are likely to still contain the feature +NOT, instantiating a local syntactic dependency, is suggested by the acceptability, in the appropriate informational environment of: Niente quasi a nessuno puoi dire! Nothing almost to anyone may (you) say

31 Unlike It. mica, pas as sentential marker only occurs immediately post-Infl:

i. $\quad$ *Jean pas $\left(n^{\prime}\right)$ est venu/Jean $\left(n^{\prime}\right)$ est venu pas

J. not is come/J. is come not

32 Cf. also the acceptability of 'almost':

II (ne) connaît presque personne

He (ne) knows almost nobody
} 
-NOT, like in Spanish, or just for +NOT, as in Standard Italian?

There is some evidence that they can function as [-NOT, +ANY]. Prima facie, non-local scope of negation can be taken to provide contrary evidence: if French personne and like N-words are indeed ambiguously specified for either value of \pm NOT, not obligatorily for + NOT, they must behave exactly like Spanish nadie, i.e. not obey ECP/locality restrictions; but we have known, at least since Kayne (1981), that they do, in cases of wide negative scope (marked by ne in the upper clause), in a highregister variety of $\mathrm{French}^{33}$ :

(69) a.* Je (n')exige que personne soit arrêté par la police

I ne require that noone be arrested by the police

intended meaning: 'I do not require that anyone be arrested by the police'

b.

Je (n')exige que la police arrête personne

I $n e$ require that the police arrest noone

'I do not require that the police arrest anyone'

However, the fact that French ne is unambiguously just a negative scope marker, not a real negation operator (hence -NOT), obliges personne to retain, and resort to, its +NOT nature (hence conditions on scope dependencies), since +ANY alone would not be licensed without being in the scope of a true negation. Expectedly, island violations are also impossible:

* Je ne m'attends à ce que rencontrer personne lui fasse plaisir

I ne expect that meeting noone pleases him

intended meaning: 'I do not expect meeting anyone to please him'

However, an N-word like personne can also co-occur with pas (though only in non-local contexts, see section 12 below), and in such cases subject-object asymmetries disappear:

33 D. Guillemin (p.c.) interestingly suggests that the difficulty experienced by several French speakers with the entire paradigm (70) may also depend on the interaction with the exceptive construction ne...que... 'only, not...but for....' 
(71) a. Je ne crois pas que personne les connaisse (from Gaatone 1971: 162)

I believe not that noone knows them

'I do not believe that anyone knows them'

b.

Je ne crois pas qu'ils connaissent personne

I believe not that they know noone

'I do not believe that they know anyone'

Thus, such paradigms lead to the conclusion that French personne is optionally specified for +NOT, like Spanish nadie, rather than obligatorily, like Italian nessuno ${ }^{34}$.

\section{MORE FRENCH}

However, there is at least one important idiosyncrasy to be added to the picture. In the scope of pas, Standard French negative quantifiers are subject to a specific 'anti-locality' restriction; they may 'concord' with a pas (cf. (72) above) but not in the same simple clause, leaving, if anything, only 'double negation' available and contrasting with the possible 'concord' reading of two N-words ${ }^{35}$ :

(72) a.? Je ne crois pas à personne

b.

$$
\begin{aligned}
& \text { 'I do not believe nobody' } \\
& \text { Je ne dis rien à personne }
\end{aligned}
$$

'I do not say anything to anybody'

Longobardi (1987) observed that, although (73)a is marked, in some other cases the French antilocality condition on pas provides neatly contrasting paradigms with Italian, Spanish, Catalan and Rumanian, which are identical in excluding a 'double negation' reading when a post-Infl negative phrase cooccurs with the simple sentential negation:

\footnotetext{
34 One may wonder whether this difference can ultimately derive from Italian niente and nessuno ( $<$ NE-ENTEM, NE-IPSU-UNUM) etymologically containing an original (IE/Latin) negative element NE-, while this is not the case with personne (<PERSONAM), rien ( $<$ REM) or nadie, nada $(<$ (REM) NATAM), respectively. Given Gallo-Italic dialects and perhaps other Romance languages, the implication, if any, only runs in one direction (i.e., diachronically, ancestrally non-negative words less readily pick up the obligatory version of [+NOT, +ANY]; the remarks in fn. 27 are also perhaps relevant). The question hinges, of course, on whether secondary analogy may be successfully invoked to explain the generalisation of the property to few originally non-negative words (especially mai <MAGIS, which equally refuses wide-scope concord from pre-Infl position).

35 In non-standard French varieties, (73)a. is found (without ne, of course) with 'concord' reading (D. Guillemin p.c.): either this register has no anti-locality at all or is like Occitan (section 14. below) and should then also admit of preverbal personne 'concording' with pas (also see the remarks on Substandard English in fn. 38).
} 
(73) a. Non è niente

b. No es nada

c. No es res

d. Nu este nimic
Italian

Spanish

Catalan

Rumanian

'It is nothing'

(74) a. Ce n'est pas rien

b.
French

'It is not nothing, i.e. it is indeed something'

Ce n'est rien

'It is nothing'

Formally, the French condition appears as a principle of syntagmatic Economy, constrained to operate under locality (only between clausemate +ANY and potential licenser):

(75) Negative Anti-locality:

a [+NOT] N-word avoids resorting only to its +ANY feature up to ungrammaticality or failure of meaning preservation.

Of course, it is still impossible to claim that Anti-locality is a principle of UG, though this would be the optimally restrictive conclusion, relieving further burden from the theory of parametric variation. Anyway, if parametrised, Anti-locality must be the unmarked case, since it is hardly learnable from positive evidence ${ }^{36}$.

\section{NON-CLAUSAL SCOPE}

Notice, finally, that condition (24) on post-Infl negative phrases only holds with respect to scope over the sentence (headed by that Infl). Thus, in the following example, Italian may reproduce the French meanings of example (75) by inserting a smaller potential scope domain, the NP headed by cosa, in order for niente to achieve scope just over it:

36 Zanuttini (1997: 10) reports an interesting Piedmontese example with post-Infl pa and gnun, with 'concord' reading ('not...anyone'). However, for it to theoretically correspond to (73)a. rather than (73)b., pa must be preliminarily shown to count as the simple propositional connective, and not as an adverbial N-word. 
(76) a. E' (una) cosa da niente

$$
\begin{aligned}
& \text { It is (a) thing of nothing } \\
& \text { 'It is nothing' }
\end{aligned}
$$

b.

Non è (una) cosa da niente

It is not(a) thing of nothing

'It is not nothing'

The same mechanism is likely to be responsible for a curious subgeneralisation: in Standard Italian a (quasi-idiomatic) reading is acceptable for certain complement PPs containing a negative quantifier in sentences without any non, while no comparable example exists, to my knowledge, for direct objects:

(77) a. Lo puoi comprare con niente

You can buy it with nothing

b. ?

Alla fine, abbiamo disquisito di niente

In the end, we debated about nothing (=no relevant matters)

(78) a.* Con quei soldi puoi comprare niente

With that money, you can buy nothing

b. * Alla fine abbiamo deciso niente

In the end, we decided nothing

It was proposed in Longobardi $(1987,2003 a)$ that the smaller potential scope domain in (78) might precisely be the PP, although work must be done to define exactly which PPs may serve such function, preventing +NOT from scoping over the verb and the entire sentence ${ }^{37}$.

\footnotetext{
37 If the constituent formed and possibly headed by coordinating items can play a similar role as smaller scope domain, one may account for examples like

i. Voglio te o nessuno

(from Ovalle and Guerzoni 2002)

'I want you or nobody else'

or

ii. Ho incontrato non Maria, ma Sofia I have met not Maria, but Sofia 


\section{OCCITAN}

So far we have seen how the possibility of being [-NOT] (essentially acting just as a scope marker) affects pre-Infl sentential negative morphemes. In principle, however, nothing bans the same possibility for post-Infl counterparts. This seems the case for Occitan (the enlightening paradigm and analysis are from Sauzet 2006) ${ }^{38}$ :

(79) a. Parla pas

speaks not

'He doesn't speak'

b.

Parla pas jamai

speak not (n)ever

'He never speaks'

c.

Degús parla pas

no(/any)body speaks not

'Nobody speaks'

d.

Degús ditz pas jamai res enluòc

no(/any)body says not (n)ever no(/any)thing no(/any)where

'Nobody ever says anything anywhere'

Of course, the relevant example (and likely acquisition trigger, cf. (87) below) is (80)c., since (80) b. could still be imputed to the possible $[ \pm N O T,+$ ANY] nature of the N-words, as in French though without Anti-locality ${ }^{39}$.

\section{QUESTIONS AND ANSWERS}

Now let me briefly touch on the problem of negative scope assignment in fragmentary answers like the a. examples of (9)-(13). The plausible solution here is that fragmentary answers literally inherit their scope properties from the question operator, which has sentential scope in the corresponding question. Thus, sentential scope of $[+\mathrm{NOT}]$ items does not require a positional specification even in

38 A similar analysis could perhaps extend to colloquial usages of Br. Portuguese nao pointed out e.g. in De Swart (2010).

39 Unless antilocality is indeed universal for languages displaying post-Infl negation and [+NOT, +ANY] N-words. The hypothesis has obvious implications, to be explored, for the analysis of Substandard English (and non-standard French, cf. fn. 34) varieties, among other things: either varieties admitting He don't do nothing can be argued to also admit Nobody don't do this, thus being like Occitan, or don't must be reanalysed as a full non post-Infl negation. 
languages with pre-Infl negation, as is shown in the following:

(80) a. Chi hai visto? Nessuno

Who did you see? Nobody
b. $\quad$ Chi non hai visto? Nessuno
Who did you not see? Nobody

Here, the first answer has single negation reading, the second double negation reading, as would be the case if nessuno 'nobody' just replaced the chi 'who' of the question.

\section{PARAMETRIC MINIMALISM}

The framework so far presented approximates to some degree of (crosslinguistic) descriptive adequacy and even of classical (Chomsky 1964) explanatory adequacy if the parameters involved are spelt out more precisely and the cues necessary to trigger their values are plausibly indicated (cf. section 20 . below). However, to pursue the goals of Chomsky's minimalist program, it is advisable to consider further standards of adequacy. Longobardi (2003b) has suggested that two such standards may be usefully termed historical adequacy and evolutionary adequacy, in principle corresponding to the two types of diachronic transmission, cultural (of I-languages) and biological (of the language faculty).

Here we will be concerned with the latter. In the Principles \& Schemata model hinted at above, parameters are not primitives of UG (the initial state of the mind $\mathrm{S}_{0}$ ), but are constructed from few general schemata by closing variables over features and categories which are still open at $\mathrm{S}_{0}$.

Now, we reconsider the three variation dimensions of section 3 . in this light.

\section{NEGATIVE QUANTIFIERS AND SYNTACTIC DEPENDENCIES}

If we tentatively limit ourselves to the parameter schemata above, the variation dimension in (5) (the 'topological mapping' parametrisation) cannot be dealt with in terms of selectional properties of a $\mathrm{Neg}^{\circ}$ head (selecting Infl or V), as suggested by Ouhalla (1990). In the present restrictive framework, the difference can rather be reduced to some parameter along the lines sketched by Zanuttini (1997: 11): crosslinguistic first Merge of a negative scope marking head ( $\mathrm{Neg}^{\circ}$, indeed) above Infl (T), with the latter probing the sentential negation overtly or covertly: hence, a parameter corresponding to schema (1)d.

Some empirical evidence seems to precisely support the restrictive approach: Zanuttini (1997) shows that in dialects of Lombardy different post-Infl positions are available for sentential negative connectives, all correlating with locally non-concord $\mathrm{N}$-words, as expected under the present approach, 
though not in a theory exclusively relying on selectional positions.

In the spirit of a topological mapping theory, especially as generalised by Hinzen and Sheehan (2011), Martin and Hinzen (2012), one may execute the idea thinking of $\mathrm{Neg}^{\circ}$ as one of the realisations (say, -Affirmative) of a general Modality head, merged above Tense; it could probe a +NOT goal with the two usual variants of such dependencies: overt checking (i.e. with an EPP feature, e.g. in Italian), covert (Long Distance) checking (e.g. in English). +NOT would never be interpreted with sentential scope unless probed by $\mathrm{Neg}^{\circ}$ (essentially Haegeman and Zanuttini's 1991 Neg Criterion). This formalises the concept of 'activation' introduced in (24). The most obvious case of overt vs. covert checking concerns simple negation: Italian non, Spanish no vs. English not, French pas etc.

In languages with a setting of this $\mathrm{Neg}^{\circ}$ parameter to 'overt', or 'strong' (in slightly more traditional terms, as adopted e.g. by Zanuttini 1997), there is no evidence of alternation between two positions for sentential negations; this may perhaps suggest that the EPP feature of $\mathrm{Neg}^{\circ}$, requiring overt matching, can be automatically satisfied through first Merge rather than by Move, i.e. no, non, nu would be base generated (perhaps as heads of $\mathrm{Neg}^{\circ}$ ): on this point $\mathrm{cf}$. a remark in section 18. below.

Now, suppose that in all these languages the Spec of $\mathrm{Neg}^{\circ}$ is not a position for an N-word to surface (cf. fn. 39 below): thus all [+NOT] quantifiers, although they should be related to this position, could never do so overtly. Therefore, nobody and personne would survive as negative quantifiers by being Long Distance interpreted with respect to their +NOT feature; but nessuno, and nadie when specified [+NOT] (e.g. always in phrases like casi nadie), would need a +NOT feature able to overtly check $\mathrm{Neg}^{\circ}$ : since they could not move to that position, they should rely on a place-holder sharing their + NOT, i.e. creating precisely the type of expletive-associate CHAIN with non or no in $\mathrm{SpecNeg}^{\circ}$ hinted at in section $8^{40}$.

Such a CHAIN, as a single complex interpretative object, will receive clausal scope on the basis of its head and will license the +ANY feature of the N-word without providing 'double negation' reading; at the same time its foot will be able to satisfy the requirements of expressions like 'almost'.

If, instead, a negative quantifier has independent checking reasons to overtly move to a variable-suitable pre-Infl position (e.g. if it is a subject or is focused), it appears to be able to check $\mathrm{Neg}^{\circ}$ anyway, and so its +NOT feature will be interpreted in either type of languages. In order to account for the latter generalisation, I suggest adopting the straightforward suggestion made by Biberauer and Roberts (2011) that $\mathrm{C}$, $\mathrm{T}$ and the functional heads occurring between them, including $\mathrm{Neg}^{\circ}$, share a number of features, whose checking may licitly take place in any such position and hold valid for all of them ${ }^{41}$.

\footnotetext{
40 Let us say that $\mathrm{Neg}^{\circ}$ in all these languages just probes the [+NOT] feature of the N-word. Consider, however, that in the spirit of parameter schema (1)f. one might expect a language in which $\mathrm{Neg}^{\circ}$ probes (pied pipes) the whole N-word or phrase containing +NOT, which could then overtly be fronted next to $\mathrm{T}$ : as a preliminary suggestion, a similar mechanism seems to correspond to the situation of Ossetic $\mathrm{N}$-words interestingly hinted at in Erschler and Volk (2011).

41 Thanks to the presence of [+ANY], a CHAIN, behaving as a single object with respect to +NOT, should also be formed between two (or more) N-words throughout Romance, so as to license all sentences like (21), (22), (37), (39), (40), (41), (65)b, (66)b, (67)a, (68), (73)b, (80).
} 
In general, movement of $+\mathrm{NOT}$ to the Modality head $\left(\mathrm{Neg}^{\circ}\right)$ could be another case of the 'movement towards the edge' strategy for making intensional material, in this case negative operators, actually interpreted (i.e. for building up reference to individuals as well as truth values of propositions, Longobardi 2005b, Hinzen and Sheehan 2011): here, the interpretation would consist of an instruction to neutralise the relevant search for reference in the ontology or invert the truth value designated by the proposition.

\section{SENTENTIAL NEGATIVE MORPHEMES}

Sentential negative morphemes are the union of two distributional subclasses, mostly defined by the parameter of the previous section (i.e. occurring either in $\mathrm{Neg}^{\circ}$ or lower). Within the resulting macroclass, the tests in section 4. define a second dimension of variation (case (6) of section 3.) and oppose cases of -NOT (formal French ne scope marker, but also Catalan no and Rumanian $n u$, as well as Occitan pas, the latter three when cooccurring with a pre-Infl negative quantifier) items to +NOT items.

Let me notice, that at first sight the ne...pas/personne/rien/jamais etc. constructions could be regarded as the same overt CHAIN of non/no in Italian/Spanish, and unlike the supposed covert relation between $\mathrm{Neg}^{\circ}$ and post-Aux not/no.../never etc. in English. However, one could not see why French differs from these other Romance languages. Furthermore, this analysis would leave unexplained the fact that ne also appears with pre-Infl N-words, and that here the pattern is the same as with Catalan and Rumanian no/nu. Finally, the account would not extend to Occitan post-Infl pas (nor to Afrikaans, which seems to have a morpheme somewhat comparable to ne, though no 'concord' N-words, according to Biberauer 2007, see parametrisation below). Therefore, one may conclude that the French-English difference here is not a case of variation of type (1)d, basically in agreement with Rowlett (1998).

A plausible parametrisation here could instead descend from schemata (1)e. and (2)a.: first of all, languages with covert checking of $\mathrm{Neg}^{\circ}$ could express the latter head phonologically (formal French $n e$, which was supposed to be -NOT, since it cannot serve as negative on its own, cf. 4. section) or not (colloquial French, Occitan, English); second, in certain languages, crosscutting the $\mathrm{Neg}^{\circ}$ parametrisation above, the sentential negative morpheme can be specified as + but also -NOT: Occitan, but also Catalan and Rumanian.

Given the assumptions of section $17 . \mathrm{a} \mathrm{Neg}^{\circ}$ remaining phonologically empty is to be postulated for Italian and Spanish as well, when an N-word occurs pre-Infl (e.g. with subject nessuno, nadie). However, this is not the case in Catalan and Rumanian, whose sentential negative morphemes no and $n u$ would be ambiguous between being like French $n e$, when they are preceded by an N-word, hence -NOT (i.e. just negative scope markers), and like Italian non, Spanish no (always +NOT), in the other cases. Now, even when we must suppose them to be-NOT, they surface in the usual pre-Infl position and display no alternations: this is not surprising if, like $n e$, they are generated as heads of $\mathrm{Neg}^{\circ}$, in such cases, but perhaps this is true of all such morphemes in pre-Infl position. 
Of course, in Occitan, Catalan and Rumanian, a universal, third-factor (Chomsky 2005), wellformedness condition on conceptual representations (non-contradiction) will ensure a disjunctive association of the two opposite values + and - NOT.

\section{FEATURE COMBINATIONS}

Consider finally the relative distribution of the feature values +NOT and +ANY (variation dimension (7) above): as seen, they are far from being semantically incompatible. They are not associated on the same category in Standard English (or in other, though not all, West Germanic languages, see Giannakidou 2002, and below), but they are so associated in the pan-Romance diasystem. This distinction is the logical consequence of the existence of a schema of type (2)a.

The internal difference opposing at least Standard Italian to French and Spanish (and more colloquial registers of Italian and other varieties) can be reduced, as hinted above, to a question of type (2) b. What is the exact formulation of this parameter, then? Or, rather, what is its unmarked setting? I have not spelt out above an acquisition cue, though it is quite obvious that the conjunctive setting of the parameter is very poorly manifested (nearly just by negative evidence); on the contrary, the more plausible occurrence of utterances like (82) with wide scope concord of the embedded negative subject in spoken Italian and in Spanish, although preverbal, is likely to be robust enough a cue for the disjunctive setting:

(81) a. Non credo che nessuno sia venuto b.

No creo que nadie vino

'I do not believe that anyone came'

We can thus take the latter setting as the unmarked one and, tentatively generalizing the observation, finally reformulate the two schemata in (2) as:

(1) g.

h.
Are $\mathrm{f}_{1}$ and $\mathrm{f}_{2}$, two grammaticalized feature values, associated on $\mathrm{X}, \mathrm{X}$ a category?

Are $\mathrm{f}_{1}$ and $\mathrm{f}_{2}$, two feature values associated on $\mathrm{X}$, optionally associated?

In other words, on the basis of this preliminary evidence, one can support the otherwise natural guess that lexical ambiguity (homonymy) is actually the marked value of feature combination; the guiding acquisition principle could be (83), a plausible third-factor condition for semiotic systems, peripherally concerning the faculty of language: 
(82) Anti-Homonymy:

Each new phonological expression is acquired associating it to a new set of non-phonological features, up to contrary evidence.

\section{PRINCIPLES, PARAMETERS, AND SCHEMATA}

Following directly is a summary of some of the universal principles tentatively hypothesized above:

(83) Potential UG Principles:

a.

$+\mathrm{NOT}$ licenses $+\mathrm{ANY}$ in its scope

b. $\quad \mathrm{Neg}^{\circ}$ is grammaticalized (probably a third factor principle) and merged immediately above $\mathrm{T}$ (presumably the minimal possible structure for it to scope over all the descriptive content of a proposition)

c.

+NOT needs scope (third factor)

d. $\quad \mathrm{Neg}^{\circ}$ must probe $+\mathrm{NOT}$ for the latter to achieve clausal scope (Haegeman and Zanuttini’s $1991 \mathrm{Neg}$ Criterion)

e.

Anti-Synonymy

f.

Anti-Homonymy

g.

Anti-Locality (if universal)

(85) below is instead a table of the parameters postulated (first column), their implicational interactions (second column), and their values (further columns, with value symbols,,+- , and 0 for implied states) in different languages, in the so-called 'Table A' representational format inaugurated in Longobardi and Guardiano (2009). The parametric implications are tentatively formulated in the most restrictive way allowed by the Romance system: 
(84) UG Parameters:

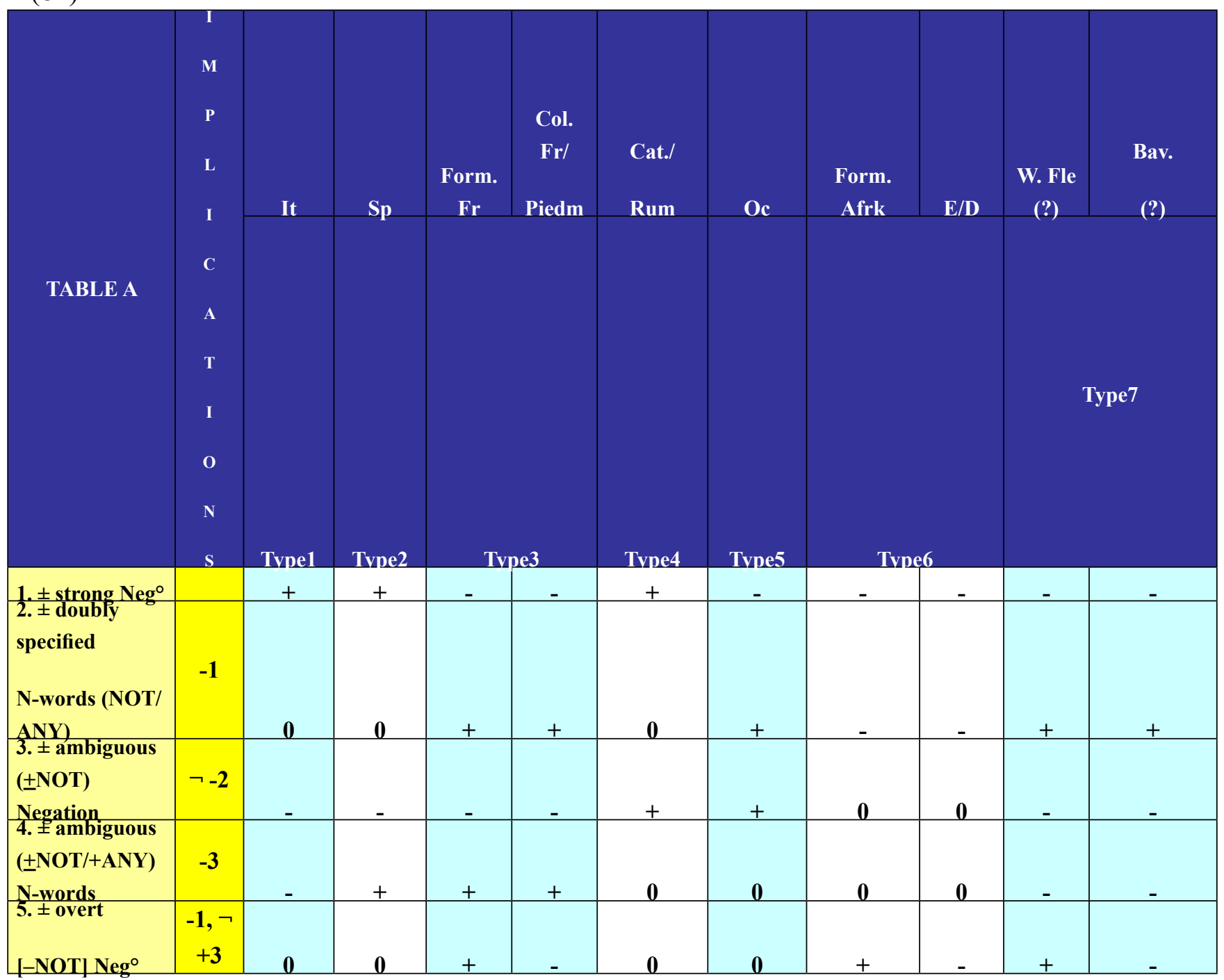

$\mathrm{P} 1$, the most basic, concerns the presence of an EPP feature on $\mathrm{Neg}^{\circ}$ (strong $\mathrm{Neg}^{\circ}$ ).

As noted in section 8., p2, asking if N-words in a language bear +ANY in addition to +NOT, is only relevant for languages with - at p1, like English and French, not for Italian or Spanish, for which it is an obliged choice, given (84)d.

P3 asks if the basic sentential negative morpheme can sometimes fail to be interpreted, i.e. drop +NOT: this seems to arise only in languages with $\mathrm{N}$-words specified for both +NOT and +ANY, perhaps as a surface diachronic generalisation to pre-Infl position of the strategy of doubling an $\mathrm{N}$-word which arises in post-Infl ones. Hence, the implication with $\neg-$ at $\mathrm{p} 2$.

P4 asks the same question with respect to dropping the feature +NOT from general N-words additionally marked [+ANY]: again it is plausible that doinng so is just obligatory for languages which already drop it from the simple negation, hence the implication with - at p3 (indirectly embodying that with $\neg-2)$. 
Finally, p5 asks if $\mathrm{Neg}^{\circ}$ always has phonological realisation, as e.g. in formal French (and apparently formal Afrikaans, T. Biberauer p.c.; also see Haegeman and Zanuttini 1996 on West Flemish en), or not. The choice seems optimally restricted to languages with - at p1 (the others must or may not use the negative morpheme according to p3) and, indeed, with $\neg+$ at $\mathrm{p} 3$ (intuitively, languages with + at p3 like Occitan would not 'need' any further marker of negative scope).

P1 to 4 predict the seven main types hinted at in the first rows of (85); wherever relevant they are further distinguished by $\mathrm{p} 5$. The assignments of actual languages to each type will be further briefly discussed in section 22. below.

(86) sums up the belonging of the parametric hypotheses each into one of the postulated schemata of UG:

(85) UG Schemata involved
p1. $=(1) \mathrm{d}$.
p3. $=(1) \mathrm{h}$.
p5. $=(1)$ e.
p2. $=(1)$ g.
p4. $=(1) \mathrm{h}$.

Given the rules (8) and (16) above, the parameters so postulated can be rather easily set on simple evidence. The structures (87), for example, fictitiously expressed with English lexicon, paired with the rough intended meanings in commas, provide evidence for the + values of the first 4 parameters respectively (in a language with linear structure otherwise similar to English):

(86) Triggers:

p1. He not is eating

'He is not eating'

p2. Say nothing to nobody

'Don't say anything to anybody'

p3. Nobody not is eating/is not eating

'Nobody is eating'

p4. He wants not that nobody eat

'He does not want anybody to eat'

Finally, p5 is certainly triggered to + by instances of double marking in simple negative clauses, though word order and the position of the two morphemes are presumably more variable than one may list here: 


\section{LINEAR AND HIERARCHICAL GENERALISATIONS}

So far, I have followed Longobardi (1987) in labelling the two crucial positions for negation and $\mathrm{N}$-words as pre- and post-Infl, improving on the accuracy of even recent literature referring to preand post-verbal position. However, the notion of precedence is increasingly regarded as derivative in syntax, especially after Kayne (1994). In fact, for all purposes so far, the notions pre- and postInfl could be replaced by c-commanding and c-commanded by Infl (or T). Actually they have to, if Zanuttini's (1997) account encoded here as p1 of (85) is correct. In this final section I will argue empirically that indeed c-command is superior to the linear formulation.

In Latin the most basic propositional negation, non, seems to unexceptionally precede the tensed verb, thus to surface in the linear order attested by almost all its successors in Romance ${ }^{42}$. Therefore, according to the generalisations of sections 5. and 7. above, the following expectations arise for Latin:

(88) a. N-words following the inflected verb should all cooccur with sentential negation and 'concord' with it;
b.
$\mathrm{N}$-words should be able to concord with each other.

Both appear to be false in formal Classical Latin (cf. Ernout and Thomas 1972: 153ff, among others) ${ }^{43}$ :

(89)
a. ...sed me moverat nemo magis quam is...
Cic. Ad Att. 7, 3, 8
...but me had-moved nobody more than he...
'...but nobody had moved me more than him...'
b. Numquam nihil agit
(from Ernout and Thomas 1972: 154)

Never nothing (s/he) does

'it is never the case that s/he does nothing'

In these respects, Classical Latin behaves rather like English (a type 6 language in (85)). The problem

42 Cf. e.g. Danckaert (2012).

43 Though they were probably correct for Colloquial Latin (Ernout and Thomas 1972: 154-5; Väänänen 1981: 152). 
can be solved through the following assumptions:

(90) a. Latin is indeed parametrised like English in (85), i.e. $\mathrm{Neg}^{\circ}$ is not strong;

b. The normal order of Latin constituents is reversed with respect to English (or Romance), perhaps in harmony with its prevailing OV status (cf. e.g. Polo 2003, Ledgeway 2011), i.e. [[[[...V] non] T] Neg] vs.

$[\mathrm{Neg}[\mathrm{T}[$ not $[\mathrm{V} \ldots]]]$;

c. Generalisation (24) FAH is indeed formulated in terms of c-command instead of precedence.

Essentially the same reasoning applies to standard German, as exemplified in (92):

(91) ...weil ich das Buch nicht gelesen habe

...because I the book not read have

'...because I did not read the book'

If one considered the linear order of nicht and habe, one should conclude that +ANY should be assigned to N-words and produce concord between two of them, contrary to fact:

(92)

...weil niemand nichts gelesen hat

...because nobody nothing read has

'...because nobody read nothing'

The assumptions (91), substituting German for Latin, may account for such facts and are corroborated by them. A possibly even clearer support for the order ...V...T Neg ${ }^{\circ}$, whatever its exact derivation, comes from Standard Afrikaans (Biberauer 2007), wherein the final nie (significantly omissible in the colloquial variety, T, Biberauer p.c.) seems to correspond to French $n e$ in $\mathrm{Neg}^{044}$, with p5 of (85) set to + , and the other one to a substantive negation like not or pas:

44 Though it could also occur higher in structure, as part of the C rather than the T system, according to Biberauer (2007 and following work), immaterially for the main argument here. 
Further evidence against the linear nature of FAH is provided by an Italian intonationally marked pattern pointed out by Ovalle and Guerzoni (2004). In some cases, with the appropriate prosody, even post-Infl direct objects may marginally fail to concord with non:

(94) Non ha mangiato, proprio NIENTE, ha mangiato un panino

Not has eaten truly NOTHING, has eaten a sandwich

'It is not the case that s/he ate nothing at all, s/he ate a sandwich'

(adapted from Ovalle and Guerzoni 2004)

A crucial feature of such structures is not only some focusing of the N-word, but also a prosodic break before it (or the whole VP). This break is similar to the one found with inverted subject and object bare nouns, when one wants them to be interpreted generically. Longobardi (2000) argued that this is due to the need for such bare nouns be outside VP, to avoid the existential reading imposed by Diesing's (1992) Mapping Hypothesis, and suggested to analyse them as topicalised and then crossed over by remnant movement of the clausal constituent. If so, (95) could have the synonymous and equally grammatical (96), obviously complying with the conditions of section 17., as its intermediate source:

(95) a. Proprio NIENTE, non HA mangiato

Truly NOTHING, not has eaten

b.

Mangiato proprio NIENTE, non HA

Eaten truly NOTHING, not has

Of course the lack of 'concord' in the latter is unsurprising, even linearly. Whatever the actual derivation, it is plausible that non does not c-command niente even in (95), and it is clear anyway that a linear generalisation fails to account for that structure, while a hierarchical one can succeed. 


\title{
22. TYPOLOGICAL COMPLETENESS
}

Given the restrictive implicational hypotheses formulated, the 10 language columns of (85) instantiate a 'completeness table' for this parameter set, i.e. the extension of the whole possible language variation produced by these 5 parameters. Actually, consider parameters 1 to 4, first : they predict exactly seven language types, all attested in the first nine columns (two pairs of columns are identical and distinguished only by $\mathrm{p} 5$ ).

Types 1-5 are all represented within Romance, with the now known articulations and with type 3 divided by 5 into formal and colloquial French; type 4 may further be instantiated in Greek and several Slavic varieties.

Type 6 is exemplified by English, but also by Latin and German (or Dutch) mutatis mutandis, i.e. modulo independent differences in constituent order; T. Biberauer (p.c.) suggests that formal Afrikaans (as opposed to colloquial Afrikaans, which should instead be like English, German and Dutch in this respect) should represent the variant of such languages with an overt scope marker.

Finally, type 7 may correspond to West Flemish, if Haegeman and Zanuttini's (1996) insights about island effects on $\mathrm{N}$-words in this language are correct, and perhaps to Bavarian (Bayer 1990). If this is the picture, we will say that the first 4 parameters are 'complete':

\section{Completeness:}

A set of parameters and of associated internal implications is complete iff their distinct value combinations are exhaustively instantiated by attested languages

\begin{abstract}
Also the set including $\mathrm{p} 5$ could be more tentatively regarded as complete if the hypothetical distinction of Bavarian and West Flemish in (85) should be accepted, alongside that between the other pairs due to p5 (e.g. formal and colloquial French, formal and colloquial Afrikaans etc.): West Flemish is hypothetically taken to belong to the first of the two columns generated by 55 for type 7 on the basis of the interpretation of the en morpheme, extensively discussed in Haegeman and Zanuttini 1996, as a scope marker.
\end{abstract}

Even if these assumptions were not fully tenable, it ought to be recalled that p5 may anyway fall under Gianollo, Guardiano and Longobardi's (2008: (6)) 'Arbitrariness Conjecture': the latter hints that parameters mainly coding morphophonological properties of lexical items (such as those of schema (1)e) are possibly affected by Saussurean arbitrariness, and thus less likely to be complete.

\section{CONCLUSIONS}


In the introduction I anticipated that a major theoretical point of Longobardi's (1987) analysis was claiming that 'double negation' and 'negative concord' languages are insufficient and unnecessary typological notions.

They are insufficient (and confusing), even descriptively, at least because they fail to capture the tripartite distinction among English, Gallo-Romance, and the rest of Romance with respect to post-Infl quantifiers, or among (formal) French, (formal) Afrikaans and German/Dutch/ English; furthermore, they are also unable to distinguish between Rumanian/Catalan and Occitan within supposed 'strict concord' languages.

They are unnecessary because propositional negative connectives (the feature +NOT) and NPIs (the feature + ANY, and conditions thereon) exist anyway -and must be mapped to specific lexical items-, as well as the distinction but logical equivalence of $\neg \exists$ and $\forall \neg$ and the difference between pre- and post-Infl negation: the sum of these concepts accounts for all the core generalisations above.

\section{REFERENCES}

Acquaviva, Paolo. 1997. The Logical Form of Negation. New York and London: Garland.

Baker, Mark. 2001. The Atoms of Language. New York: Basic Books.

Bayer, Josef. 1990 What Bavarian Negative Concord Reveals about the Syntactic Structure of German. In Grammar in Progress, Joan Mascaró \& Marina Nespor (eds), 13-24. Dordrecht: Foris.

Bernini, Giuliano \& Ramat Paolo. 1992. La frase negativa nelle lingue d'Europa. Bologna: il Mulino.

Berwick Robert \& Chomsky Noam. 2011. The Biolinguistic Program: The Current State of its Evolution and Development. In The Biolinguistic Enterprise. New Perspectives on the Evolution and Nature of the Human Language Faculty, Anna Maria Di Sciullo \& Cédric Boeckx (eds), 19-41. Oxford: Oxford University Press.

Biberauer, Theresa. 2007. A closer look at Negative Concord in Afrikaans. Stellenbosch Papers in Linguistics PLUS (35): 1-51.

Biberauer, Theresa \& Zeijlstra Hedde. 2012. Negative Concord in Afrikaans: filling a typological gap. Journal of Semantics 29(3): 345-371.

Biberauer, Theresa \& Roberts Ian. 2011. Negative words and related expressions: a new perspective on some familiar puzzles. Ms. University of Cambridge. 
Biberauer, Theresa \& Richards Mark. 2006. True Optionality: when the grammar doesn't mind. In Minimalist Essays, Cédric Boeckx (ed.), 35-67. Amsterdam: John Benjamins.

Boeckx, Cédric. 2011. Approaching parameters from below. In The Biolinguistic Enterprise. New Perspectives on the Evolution and Nature of the Human Language Faculty, Anna Maria Di Sciullo \& Cédric Boeckx (eds), 205-221. Oxford: Oxford University Press.

Borer, Hagit. 1984. Parametric Syntax. Dordrecht: Foris.

Bortolussi, Luca, Sgarro, Andrea, Longobardi, Giuseppe \& Guardiano, Cristina. 2011. How many possible languages are there? In Biology, Computation and Linguistics, Gemma Bel-Enguix, Veronica Dahl, \& M. Dolores Jiménez-López (eds), 168-179. Amsterdam: IOS Press.

Carlson, Greg N. 1977. A unified analysis of the English bare plural. Linguistics and Philosophy 1: 413-456.

Chomsky, Noam. 1964. Current Issues in Linguistic Theory. In The Structure of Language, Jerry A. Fodor \& Jerrold J. Katz (eds), 50-118. Englewood Cliffs NJ: Prentice Hall.

Chomsky, Noam. 1981. Lectures on Government and Binding. Dordrecht: Foris.

Chomsky, Noam. 1986. Knowledge of Language. New York: Praeger.

Chomsky, Noam. 2005. Three Factors in Language Design. Linguistic Inquiry 36: 1-22.

Crisma, Paola. 2012. Quantifiers in Italian. In Handbook of Quantifiers in Natural Language, Edward L. Keenan \& Denis Paperno (eds), 467-534. Dordrecht: Springer.

Danckaert, Lieven. 2012. The decline of Latin VOAux: Neg-incorporation and syntactic reanalysis. Paper presented at DiGS 14, Lisbon, July 4-6 2012.

De Swart, Henrïette. 2010. Expression and interpretation of negation: an OT typology [Studies in Natural Language and Linguistic Theory 77]. Dordrecht: Springer.

Diesing, Molly. 1992. Indefinites. Cambridge Mass: MIT Press.

Ernout, Alfred \& Thomas François. 1972. Syntaxe Latine. Paris: Klincksieck.

Erschler, David \& Volk Vitaly. 2011. On Negation, Negative Concord, and Negative Imperatives in Digor Ossetic. In Topics in Iranian linguistics, Geoffrey Haig, Agnes Korn, Pollet Samvelian \& Simin Karimi (eds), 135-150. Wiesbaden: Reichert. 
Español-Echevarría, Manuel. 1994. A Typology for NPI-Licensing. Ms. UCLA.

Espinal, M. Teresa. 2000. On the Semantic Status of N-words in Catalan and Spanish. Lingua 110: 557-580.

Gaatone, David. 1971. Etude descriptive du système de la négation en français contemporain. Genève: Librairie Droz.

Giannakidou, Anastasia. 1998. Polarity Sensitivity as (Non)veridical Dependency. Amsterdam: John Benjamins.

Giannakidou, Anastasia. 2002. N-words and negative concord. Ms. University of Chicago.

Gianollo, Chiara, Guardiano, Cristina \& Longobardi, Giuseppe. 2008. Three fundamental issues in parametric linguistics. In The limits of syntactic variation, Theresa Biberauer (ed.), 109-142. Amsterdam: John Benjamins.

Guerzoni, Elena. 2006. Intervention effects on NPIs and feature movement: towards a unified account of intervention. Natural Language Semantics 14: 359-398.

Haegeman, Liliane. 1995. The Syntax of Negation. Cambridge: Cambridge University Press.

Haegeman, Liliane \& Zanuttini Raffaella. 1991. Negative Heads and the Neg-criterion, The Linguistic Review 8: 233-251.

Haegeman, Liliane an\& Zanuttini Raffaella. 1996. Negative Concord in West Flemish. In Parameters and Functional Heads. Essays in Comparative Syntax, Adriana Belletti \& Luigi Rizzi (eds.), 117-179. Oxford: Oxford University Press.

Haspelmath, Martin. 1997. Indefinite pronouns. Oxford: Oxford University Press.

Herburger, Elena. 2001. The negative concord puzzle revisited. Natural Language Semantics 9: 289333.

Hinzen, Wolfram \& Sheehan, Michelle. 2011. Moving Towards the Edge: the Grammar of Reference. Ms. University of Durham.

Jaeggli, Osvaldo. 1984. Subject Extraction and the Null Subject Parameter. In Proceedings of NELS 14, Charles Jones \& Peter Sells (eds), 132-53. Amherst, Mass.: GLSA, University of Massachusetts at Amherst. 
Kayne, Richard. 1981. Two Notes on the NIC. In Theory of Markedness in Generative Grammar, Adriana Belletti, Luciana Brandi \& Luigi Rizzi (eds.), 317-346. Pisa: Scuola Normale Superiore.

Kayne, Richard. 1994. The Antisymmetry of Syntax. Cambridge, Mass: MIT Press.

Kayne, Richard. 2010. Comparisons and Contrasts. Oxford: Oxford University Press.

Kroch, Anthony. 1989. Reflexes of grammar in patterns of language change. Language Variation and Change 1: 199-244.

Kuroda, Shige-Yuki. 1988. Whether we agree or not: A comparative syntax of English and Japanese. Linguisticae Investigationes 12: 1-47.

Ladusaw, William. 1993. Negation, Indefinites, and the Jespersen Cycle. In Proceedings of the Nineteenth Annual Meeting of the Berkeley Linguistics Society 19, 437-446.

Laka, Itziar, M. 1990. Negation in syntax: On the nature of functional categories and projections. $\mathrm{PhD}$ dissertation, MIT.

Ledgeway, Adam. 2011. From Latin to Romance. Oxford: Oxford University Press.

Lightfoot, David. 2006. Minimizing government: Deletion as cliticization. The Linguistic Review 23: 97-126.

Linebarger, Marcia. 1980. The Grammar of Negative Polarity. PhD dissertation, MIT.

Longobardi, Giuseppe. 1987. The three systems of Romance negation. Paper presented at the X GLOW Colloquium, Workshop on Generative Dialectology, Venice. April 2, 1987.

Longobardi, Giuseppe. 1988. I quantificatori. In Grande Grammatica Italiana di Consultazione, Lorenzo Renzi (ed.), 645-696. Bologna: il Mulino.

Longobardi, Giuseppe. 1991. In Defense of the Correspondence Hypothesis: island effects and parasitic constructions in Logical Form. In Logical Structure and Linguistic Structure, C.-T. James Huang \& Robert May (eds.), 149-196. Dordrecht: Kluwer.

Longobardi, Giuseppe. 1996. The Syntax of N-raising: a minimalist theory. Utrecht: OTS Working Papers.

Longobardi, Giuseppe. 2000. Postverbal subjects and the Mapping Hypothesis. Linguistic Inquiry 
31(4): 691-702.

Longobardi, Giuseppe. 2003a. Three Parameters of Romance Negation. Studi e Saggi Linguistici 4041: 181-186 [Atti del convegno di studi in memoria di Tristano Bolelli, Giovanna Marotta (ed.), Pisa: ETS].

Longobardi, Giuseppe. 2003b. Methods in Parametric Linguistics and Cognitive History. Linguistic Variation Yearbook 3: 101-138.

Longobardi, Giuseppe. 2005a. A Minimalist Program for Parametric Linguistics? In Organizing Grammar: Linguistic Studies for Henk van Riemsdijk, Hans Broekhuis, Norbert Corver, Marinus Huybregts, Ursula Kleinhenz \& Jan Koster (eds), 407-414. Berlin/New York: Mouton de Gruyter.

Longobardi, Giuseppe. 2005b. Toward a Unified Grammar of Reference. Zeitschrift für Sprachwissenschaft 24: 5-44.

Longobardi, Giuseppe. 2012. Convergence in parametric phylogenies: homoplasy or principled explanation? In Parameter Theory and Linguistic Change, Charlotte Galves, Sonia Cyrino, Ruth Lopes, Filomena Sandalo \& Juanito Avelar (eds), 304-319. Oxford: Oxford University Press.

Longobardi, Giuseppe \& Guardiano, Cristina. 2009. Evidence for Syntax as a Signal of Historical Relatedness. Lingua 119(11): 1679-1706 [spec. issue The Forests behind the Trees, John Nerbonne (ed.)].

Martín, Txuss \& Hinzen, Wolfram. 2012. The grammar of the essential indexical. Ms. University of Durham.

Martín-González, Javier. 2002. The Syntax of Sentential Negation in Spanish. PhD dissertation, Harvard University.

Martins, Ana Maria. 2000. Polarity Items in Romance: Underspecification and Lexical Change. In Diachronic Syntax: Models and Mechanisms, Susan Pintzuk, George Tsoulas \& Anthony Warner (eds.), 191-219. Oxford: Oxford University Press.

Ouhalla, Jamal. 1990. Sentential Negation, Relativized Minimality and the aspectual status of auxiliaries. The Linguistic Review 7: 183-231.

Ovalle, Luis A. \& Guerzoni, Elena. 2004. Double Negation, Negative Concord and Metalinguistic Negation. In Proceedings of the Chichago Linguistics Society Meeting: The Main Session, Mary Andronis, Erin Debenport, Anne Pycha \& Keiko Yoshimura (eds), 15-31. Chicago: CLS Publications. 
Penka, Doris. 2011. Negative indefinites. Oxford: Oxford University Press.

Penka, Doris \& Zeijlstra Hedde. 2010. Negation and polarity: an introduction. Natural Language and Linguistic Theory 28: 771-786.

Polo, Chiara 2003. Word order between morphology and syntax. Padova: Unipress.

Progovac, Ljiljana. 1994. Positive and Negative polarity: a binding approach. Cambridge : Cambridge University Press.

Quer, Josep. 1993. The Syntactic Licensing of Negative Items. MA thesis, Universitat Autònoma de Barcelona.

Rizzi, Luigi. 1982. Issues in Italian Syntax. Dordrecht: Foris.

Rizzi, Luigi, \& Shlonsky, Ur. 2006. Strategies of subject extraction. In Interfaces + Recursion $=$ Language? Chomsky's Minimalism and the View From Syntax- Semantics, Hans M. Gärtner \& Uli Sauerland (eds), 115-160. Berlin: Mouton de Gruyter.

Roberts, Ian. 2010. Clitics, Incorporation and Head Movement. Cambridge, MA: MIT Press.

Roberts, Ian. 2011. Rethinking Comparative Syntax. ERC Advanced Grant 2010 project, University of Cambridge.

Roberts, Ian \& Roussou Anna. 2003. Syntactic Change. A Minimalist approach to Grammaticalization. Cambridge: Cambridge University Press.

Rowlett, Paul. 1998. Sentential Negation in French. Oxford: Oxford University Press.

Sauzet, Patrick. 2006. Doubling phenomena in Occitan. Paper presented at Workshop on Doubling Phenomena in European Dialects, Meertens Instituut, Amsterdam. March 16-18, 2006.

Sells, Peter \& Kim, Shin-Sook. 2006. Korean NPIs Scope Over Negation. Language Research 42(2): 275-297.

Solà, Joan. 1972. Estudis de sintaxi catalana. Barcelona: Edicions 62.

Sportiche, Dominique. 1986. Zibun. Linguistic Inquiry 17(2): 369-374.

Vallduví, Enric. 1994. Polarity items, N-words and minimizers in Catalan and Spanish. Probus 6: 
263-274.

Väänänen Veikko. 1981. Introduction au latin vulgaire, 3rd ed. (revue et augmentée), Paris: Klincksieck.

Watanabe, Akira. 2004. The Genesis of Negative Concord. Linguistic Inquiry 35: 559-612.

Zanuttini, Raffaella. 1997. Negation and Clausal Structure: A Comparative Study of Romance Languages. Oxford: Oxford University Press.

Zanuttini, Raffaella. 2001. Sentential Negation. In The Handbook of Contemporary Syntactic Theory, Mark Baltin \& Chris Collins (eds), 511-535. New York: Blackwell.

Zeijlstra, Hedde. 2004. Sentential negation and negative concord. PhD dissertation, University of Amsterdam.

Zeijlstra, Hedde. 2008. Negative Concord is Syntactic Agreement. Ms. University of Amsterdam. 